\title{
Alianza religiosa y realeza sagrada en el antiguo Michoacán
}

\author{
Roberto MARTÍNEZ GONZÁlEZ \\ Instituto de Investigaciones Históricas, Universidad Nacional Autónoma de México \\ nahualogia@yahoo.com.mx
}

Recibido: 22 de marzo de 2010

Aceptado: 19 de julio de 2010

\section{RESUMEN}

Como continuación de un trabajo anterior sobre la realeza sagrada entre los tarascos, el objetivo central de este artículo es describir el tipo de vínculo específico que unía al cazonci con la deidad nacional. Primeramente demostraremos que, en el proceso iniciático del gobernante, la alianza con la divinidad legitima su función. Explorando el sistema simbólico tarasco, mostraremos que la relación entre el dios, el pueblo, el reino y el señor se describe en términos de matrimonio filiación y familia política. Explicaremos cómo es que esta clase particular de nexo también puede involucrar a la esposa del cazonci y cuáles son los mecanismos que permitían a las mujeres asumir posiciones de poder. Por último, describiremos el rol central de la alianza en la constitución mítica del estado tarasco.

Palabras clave: Alianza religiosa, realeza sagrada, tarascos, p'urhépecha

\section{Religious Alliance and Sacred Royalty in Ancient Michoacán}

\begin{abstract}
Following a precedent work about the Tarascan sacred royalty, the main goal of this paper is to describe the specific type of link that unites the cazonci to the national god. Firstly, we will demonstrate that, in the governor initiatory process, the alliance with the divinity legitimizes his role. Exploring the Tarascan symbolic system, we will show that the relation between the god, the people, the kingdom and the king is described in terms of marriage, filiation and family in law. We will explain how this particular kind of link may also involve the $c a-$ zonci's wife and which mechanisms allow women to assume power roles. Finally, we will describe the central role of the alliance in the mythical constitution of the Taracan state.
\end{abstract}

Key words: Religious alliance, sacred royalty, Tarascan, P'urhépecha

SUMARIO: 1. Introducción. 2. Iniciación y contacto directo en el antiguo Michoacán. 3. La alianza divina. 4. La alianza en femenino. 5. La alianza de los hombres en la historia mítica. 6. Consideraciones finales. 7. Referencias bibliográficas.

\section{Introducción}

En un trabajo anterior (Martínez González 2009) vimos que, en la Relación de Michoacán ${ }^{1}$, la deidad patrona de los uacúsecha parece tener una existencia paralela a la de la sociedad. La aparición del dios patrono marca el origen de un determinado grupo, sus cualidades son atribuidas a la influencia divina, su historia y destino son descritos

\footnotetext{
${ }^{1}$ Espejel (2008) encuentra semejanzas entre la Relación y las Siete Partidas de Alfonso X el Sabio; a partir de ello, sostiene que el papel del fraile redactor fue más activo de lo que él hizo creer, que «en su papel de intérprete no transcribió tan fielmente las palabras de sus informantes y que, de hecho, su interpretación afectó profundamente la imagen de la sociedad que plasmó en el documento». No obstante esta autora no descarta la posibilidad de comprender a través de dicho escrito la visión indígena del mundo: El fraile introdujo el concepto de justicia como principal medio para conservar el orden de Dios. Sin embargo, también se reconoce una voz
} 
como propios de la divinidad, el fraccionamiento del bulto sagrado se asocia a la división del pueblo o la incorporación de nuevas facciones sociales, mientras que su pérdida acarrea el sometimiento o destrucción de la colectividad. Actuando además como guía y representante del territorio ocupado la deidad se nos presenta, tanto como una suerte de doble sobrenatural de la comunidad, como a manera de memoria simbólica de los eventos que le afectan.

Dijimos, no obstante, que el numen tutelar no era el único al que los tarascos rendían culto sino que, por el contrario, también había otras deidades descritas como extranjeras a las que se adoraba. Vimos que la relación con los propios dioses es tratada en términos de filiación (el pueblo es su descendiente) y propusimos que la que se establece con las divinidades ajenas podría ser entendida bajo la lógica de la alianza (el dios del otro es familia política del pueblo).

Por último, explicamos que no todos los seres humanos mantienen la misma clase de vínculos con las deidades sino que es el cazonci o gobernante supremo, también llamado irecha, quien funge como representante del patrono ante los hombres. Y es gracias a esta función que debe encargarse tanto de hacer que se cumplan sus designios sobre la tierra como de actualizar las alianzas con otros dioses a través de los matrimonios que forja con sus representantes. Vimos que, aunque la herencia debió tener gran importancia, lo que se resalta en la adquisición del poder señorial es el contacto directo con la divinidad tutelar. Así, es el soberano quien establece el vínculo con el numen pero, tratándose de un representante de la comunidad, éste se hace extensivo a toda la sociedad. De modo que, considerando que el irecha está en lugar de la deidad, observamos que éste tiene la doble función de significar a la sobrenaturaleza -es decir, la naturaleza dotada de sentido por el hombre- frente al pueblo y al pueblo ante la sobrenaturaleza. En tales condiciones, no resulta asombroso que en su papel de mediadores se atribuya a los mandatarios la capacidad de dialogar con las divinidades ${ }^{2}$.

Sin embargo, un aspecto de la realeza sagrada que no abordamos con suficiente profundidad es el de la naturaleza de las relaciones entre el señor y su deidad patrona;

indígena en la que el discurso se ordena alrededor del culto a la deidad del fuego. «Dependiendo de la clave con que se lean, los datos de la Relación adquieren diferentes significados y, en consecuencia, cada lectura genera una imagen distinta de los tarascos».

${ }^{2}$ López Austin (1976) explica la relación con la deidad patrona en términos de una «fuerza»o «poder» que se infundía en cada uno de los miembros de la colectividad. Este vínculo se trasmitía por herencia tanto patrilineal como matrilineal, pero el producto del matrimonio con extranjeras implicaba, por la mezcla, el empobrecimiento de dicho capital. En este esquema, no todos los individuos de una colectividad mantenían las mismas relaciones con el dios, sino que quienes entraban en contacto directo con él adquirían una parte de su poder. Asimismo, sus descendientes estaban dotados de una facultad especial para comunicarse con lo divino y por ello eran más aptos para mandar (López Austin 1976: 219). La ofrenda de fuego y la penitencia ayudarían a estrechar la relación entre el mandatario y la deidad, mientras que las actitudes antisociales, como el adulterio y la embriaguez, tenderían a debilitarla. La existencia de un linaje estaría dada por una secuencia de señores íntimamente ligados al dios tutelar: «Son los señores, más bien, recipientes de energía. No había, pues identificación absoluta, aunque sí la noción de fuerza que penetraba y enriquecía al gobernante» (López Austin 1976: 222). Dicha fuerza no era infinita sino que, siendo muy viejo el señor, ésta comenzaba a extinguirse y, por tal motivo, era común que se trasmitiera el cargo a la generación siguiente estando en vida el irecha antecesor (López Austin 1976: 222). Sin embargo, aunque pensar los mecanismos de legitimación del gobierno en términos de una fuerza, poder o fuego divino resulta sumamente ilustrativo, es importante señalar que nuestra fuente jamás lo refiere así, es más, los vocablos «fuerza» y «poder» se encuentran absolutamente ausentes en la Relación de Michoacán. 
ese es el tema sobre el que versa este ensayo. Ya que para comprender la alianza sobrenatural es necesario comenzar por establecer qué es lo que resulta de ella, el primer apartado de este trabajo estará dedicado al análisis de ese proceso que, en ocasiones, se nos presenta como una iniciación. En un segundo momento buscaremos entender el vínculo dios-cazonci a la luz de los modelos de alianza entre los humanos -el matrimonio y el «hermanamiento»-. Exploraremos el tema de los poderes femeninos para definir mejor el modo en que se distribuyen las funciones sociales a partir del lazo que se establece con la deidad. Y, por último, procuraremos definir la lógica de la alianza en el ámbito de la mito-historia fundacional tarasca.

\section{Iniciación y contacto directo en el antiguo Michoacán}

Cuando comparamos las diferentes narraciones de contactos directos con las divinidades que aparecen en las fuentes, encontramos dos elementos que tienden a mantenerse constantes: el descubrimiento de las deidades en un cerro - que se presenta en el encuentro de Curicaueri por Ticatame, el proceso iniciático de Hiripan y Tangaxoan y el hallazgo de los ídolos en la fundación de Pátzcuaro-y la presencia de la sobrenaturaleza al pie de un encino -que no sólo se ve en el caso de los sobrinos de Tariácuri y la mujer poseída por Cuerauaperi sino también en las apariciones de vírgenes milagrosas entre los p'urhépecha contemporáneos (Alcalá 2008: ff37v, 72v, 62v, 116-124v; Gallardo 2009: comunicación personal) ${ }^{3}$ - A ello se suma que el uso iniciático de oquedades naturales figura tanto en el relato de ascensión de Hiripan y Tangaxoan como en el caso de ciertos ritualistas contemporáneos (Velásquez Gallardo 2000: 124-132).

Esto nos muestra que tales eventos forman parte de un mismo sistema de representaciones y, por consiguiente, las similitudes o diferencias entre ellos pueden ayudarnos a comprender la singularidad del contacto directo del gobernante con la deidad ${ }^{4}$.

En primer lugar tenemos el caso de la manceba del señor de Ucareo a la que «toma» la diosa Cuerauaperi para revelarle la llegada de los españoles:

«Entonces púsola allí y desatose una jícala, como escudilla, que tenía atada en sus naguas, y tomó agua y lavó aquella jical, y echó un poco de agua en ella y echó dentro de la jical una como simiente blanca e hizo un brebaje y dióselo a beber [a] aquella mujer y mudole el sentido [...] Y fuese por el camino aquella mujer y luego [se] encontró en el camino con una águila que era blanca y tenía una berruga grande en la frente. Y empezó el águila a silbar y a enherizar las plumas y con unos ojos grandes, que decía ser el dios Curicaberi [...] Díjole el águila: 'sube aquí encima de mis alas' [...] Levantose el águila con ella y empieza a silbar y llevola a un monte [llamado Xanóata hucazio], donde está una fuente caliente que hay en ella piedra azufre, y llevola por aquel monte volando con ella [...] Vio aquella mujer que estaban asentados todos los dioses de la provincia» (Alcalá 2008: ff36v-37v).

\footnotetext{
${ }^{3}$ Incluso en la estación rupestre de Caránguirio, Michoacán, pudimos observar el grabado contemporáneo de una Virgen de Guadalupe al pie de un encino (Martínez, Castilleja y Oliveros en prensa).

${ }^{4}$ Por su semejanza, algunas de las etapas de la iniciación de estos personajes parecen recrear los episodios más importantes de la historia mítica uacúsecha: el encuentro de la divinidad en el cerro Zacapu-Pátzcuaro, la erección de templos, la guerra y el primer sacrificio, etc.
} 
La diferencia principal con el caso de nuestro interés es que, no habiendo un pacto explicito entre la muchacha y la deidad, lo relatado se queda en el ámbito de la eventualidad. En cambio, con los futuros gobernantes vemos que, aunque se trata de un contrato personal entre el humano y la deidad, las obligaciones que se derivan son cumplidas de manera colectiva -el gobernante no es el único que ofrenda al dios sino también el pueblo en general-. De hecho, parece ser que los beneficios adquiridos no sólo atañen a los pactantes sino que, de algún modo, también afectan a sus descendientes gobernantes; pues para la elección de un nuevo cazonci se habla del deber de aportar leña a los templos, de las incursiones militares que hacía el recién elegido para obtener cautivos para sacrificios, y de una cierta velación en la casa de los papas de Curicaueri, pero en ningún momento se dice que haya debido entrar en contacto directo con los dioses (Alcalá 2008: ff32-35v).

En segundo lugar tenemos que, para poder asumir su función, en época contemporánea algunos de los sïkwamecha -ritualistas de carácter ambivalente vinculados al proceso de salud-enfermedad- debían entrar en contacto directo con una divinidad parecida al demonio cristiano llamada Terungutpiri. En el pacto iniciático «el aprendiz le pedirá que le de los poderes mágicos para poder hechizar y curar a una persona. Terúngutpiri le contestará que sí le ayudará, pero con la condición de que mate a la gente por medio de hechizos. Si el aprendiz acepta el contrato está hecho» (Velásquez

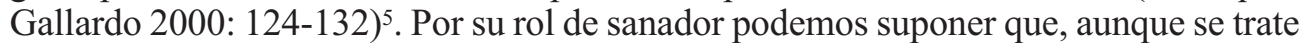
de una relación individual, los beneficios de la función adquirida por el sikkwame se derraman hacia la totalidad de la comunidad y, por tal razón, su costo también debe ser pagado por ella. Aunque aquí sí existe un pacto explícito, es importante resaltar que el contrato entre especialista y numen es individual e intrasmisible y, por consiguiente, cada nuevo ritualista debe entablar su propia negociación. A pesar de que tal episodio no es suficiente para la obtención del poder sobrenatural, cabe aclarar que para el sïkwame el resultado de la alianza es la adquisición de un rol diferente, mientras que conocemos casos de individuos que ya siendo cazonci seguían buscando el encuentro con los dioses (Martínez González 2009: 60).

La última clase de contacto directo descrita por las fuentes no se refiere a un episodio iniciático sino a ciertos personajes llamados curich o curitiecha, específicamente dedicados a la posesión y la difusión de los mensajes que recibían de las deidades.

«Revestíase el demonio en uno de los indios que estaban dedicados para los templos, como n[uest]ros sacerdotes, y aquel, a voces, como predicador, puesto en lo alto del cuy, hablaba al pueblo [...] Lo que les decía era que le sacrificacen sangre los naturales deste pue[bl]o y que, para ello, se horadasen las lenguas y las orejas, y que a los que cautivaban en las guerras, q[ue] los abriesen por las costillas del lado izquierdo y les sacasen el corazón y se lo ofreciesen [...] El nombre de los sacerdotes, si así se les puede llamar, era curich $[\ldots]$ Cuando les hablaba y predicaba, estaba dentro dellos su dios [... ] Entendían que aquella habla no era de hombre humano ni, las palabras que les decía, no eran conforme a como después les hablaba» (Relación de Tiripitio 1987: 341-342) ${ }^{6}$.

\footnotetext{
${ }^{5}$ Cabe aclarar que aquí el contacto con las deidades no es suficiente para adquirir este rol sino que además se requiere pertenecer a una familia de sïkwamecha, poseer rasgos físicos específicos, ser de «sangre fuerte» y pasar por un proceso de aprendizaje al lado de un especialista más experimentado (Velásquez Gallardo 2000: 124-132).

${ }^{6}$ De acuerdo con la Relación de Michoacán (Alcalá 2008: f11), los curitiecha «eran como predicadores y
} 
Se reconoce un componente hereditario tanto en los curitiecha como en los gobernantes (Alcalá 2008: f11). En ambos casos se supone que en el cuerpo del individuo se manifiestan tanto la personalidad humana como la sobrenatural (Martínez González 2009: 59; Relación de Tiripitio 1987: 348). Entre otras cosas, la presencia de la divinidad en el cuerpo del cazonci se deduce del hecho de que tras la muerte sus restos se conviertan en reliquias (Martínez González 2009: 61). A ello se suma que según las fuentes también los mandatarios tenían funciones sacerdotales; se podría objetar que la Relación de Michoacán (Alcalá 2008: f11) no incluye al cazonci entre los curitiecha sino entre los axámencha, «sacrificadores»; sin embargo, es preciso aclarar que como apunta Espejel (2008: 223-224) los atributos de estas dos clases tienden a confundirse.

La diferencia fundamental entre el sacerdote y el señor es que, a través de la posesión, el primero encarna a la deidad mientras que el segundo se conforma con representarla; es su modelo y sustituto. En el proceso iniciático señorial, el contacto es el medio que hace posible la alianza en tanto que, en el sacerdocio, éste es la finalidad misma de la acción ritual.

En resumen, podemos observar que la alianza no sólo concierne al cazonci y la divinidad sino que las obligaciones que de ella se desprenden involucran a la totalidad de la colectividad. No se trata de hechos singulares sino que cada nuevo encuentro contribuye al reforzamiento de los vínculos entre el dios y un linaje particular de tal modo que, cuando muere un señor, la alianza le sobrevive. Por último, notamos que a diferencia de otros casos, el contacto directo que los gobernantes tarascos establecen con sus deidades tutelares no determina su función sino su legitimidad, puesto que algunos nunca lo consiguieron.

La pregunta que ahora tocaría resolver es: ¿qué tipo de relación es la que establece el vínculo entre el gobernante y la divinidad patrona?

\section{La alianza divina}

Partiendo del supuesto de que la socialización con la sobrenaturaleza toma como modelo las relaciones que los humamos establecen entre sí, tendríamos que comenzar por ver qué tipos de alianza son las que describen nuestras fuentes; la Relación de Michoacán nos ofrece dos opciones al respecto, el matrimonio y algo que pudiéramos denominar el «hermanamiento».

Si comparamos las descripciones de los casamientos con los relatos iniciáticos de los gobernantes, podemos encontrar varias similitudes. Para ello tomaremos como ejemplo el caso de Hiripan y Tangaxoan pues es, con mucho, el mejor documentado (ver Cuadro 1). El primer paso en la alianza sobrenatural es el ofrecimiento de sangre, leña y alimentos a la deidad. Paralelamente, las negociaciones matrimoniales solían empezar con una serie de regalos al futuro suegro ${ }^{7}$. Aparentemente, más que un inter-

hacían las cirimonias». El templo en el que se encontraba este sacerdote era, hasta cierto punto, equivalente al cerro en el que los gobernantes y la manceba del señor de Ucareo encuentran a los dioses -recordemos que, en lugar de ir al monte, Hiquingare hace sus «ahumadas» en el templo-.

${ }^{7}$ «Sabía un señor o cacique que tenía una hija otro señor o prencipal, o que estaba con su madre, y enviaba 
Cuadro 1: Alianza matrimonial y alianza sobrenatural

\begin{tabular}{|c|c|c|}
\hline & Alianza sobrenatural & Alianza matrimonial \\
\hline 1 & Se ofrece leña, sangre y alimento a la deidad & Se ofrecen regalos al futuro suegro \\
\hline 2 & Se recibe un fragmento del bulto sagrado & \\
\hline 3 & Se erigen templos y hacen sacrificios & \\
\hline 4 & Negociación e intercambio con la deidad & Negociación e intercambio con el suegro \\
\hline 5 & Entrega de atributos señoriales & Envío de la novia y celebración de la boda \\
\hline 6 & $\begin{array}{l}\text { Conquista del pueblo (se recibe el territorio } \\
\text { de la deidad) }\end{array}$ & $\begin{array}{l}\text { El suegro indica el lugar donde la pareja ha de } \\
\text { vivir }\end{array}$ \\
\hline
\end{tabular}

cambio, aquí debió tratarse de una negociación pues, así como un hombre no está forzado a entregar a su hija al primero que lo solicite, la ofrenda, por cuantiosa que sea, no obliga a la deidad a responder (véase, por ejemplo, el caso de Tariácuri). Al menos en lo tocante a los futuros gobernantes, la generosidad del don debió ser de gran importancia, pues sabemos que a veces esta actividad podía prolongarse durante años. En el caso de Hiripan y Tangaxoan, el episodio de ofrenda concluye con la recepción de un fragmento del bulto sagrado, la erección de templos y el inicio del sacrificio ${ }^{8}$; nótese que con Tariácuri sucede más o menos lo mismo, primero erige los templos en Petazequa y luego organiza un sacrificio humano para inaugurarlos -nada de esto se presenta en el ceremonial matrimonial-. En la segunda fase, después del encuentro, se produce una suerte de contrato en el que los dioses piden tesoros, culto y ofrendas a cambio del señorío y los atributos del poder -mantenimientos, mujeres, joyas, esclavos y una población grande-, algo que sería comparable a la entrega de la novia por parte del suegro. Y, por último, la conquista del territorio por la deidad sería coincidente con la asignación del espacio para vivir por parte del suegro (Alcalá 2008: ff116-124v, 24-29v).

Obviamente, es poco probable que el gobernante haya sido tratado como marido o esposa de la deidad pues, además de que en los relatos iniciáticos no existe ninguna alusión a lo sexual, cabe recordar que Curicaueri y el cazonci son del mismo sexo. En el caso de la alianza con Xaratanga, se aclara que se trata de una mujer vieja y, según se muestra en la imagen correspondiente, ni siquiera se atreve a tocar a su elegido con la mano sino que usa un palo para despertarlo (Alcalá 2008: f122).

En cambio observamos que, hasta cierto punto, la función del dios con el que el señor se alía es similar a la del suegro; es con él con quien se hacen los arreglos matrimoniales - «nunca preguntaban a la mujer si se quería casar con hulano, bastaba que sus padres o parientes lo concertaban» (Alcalá 2008: f29)-con quien se establecen

un mensajero con sus presentes a pedir aquella mujer para su hijo» (Alcalá 2008: f26).

${ }^{8}$ Aparentemente la piedra-Curicaueri tiene cierta capacidad de obrar e influye sobre el comportamiento de sus poseedores, pues Tariácuri explica «¿Qué mis hijos no tienen la culpa?, ¿qué no lo hicieron de su autoridad sino que yo les di aquella piedra?» (Alcalá 2008: f119).

${ }^{9}$ Una vez que aceptaba el matrimonio el gobernante enviaba a un sacerdote para entregar a su hija $-\gg$ yo inviaré uno que la lleve»-; ya iniciada la ceremonia, el sacerdote dice «sed los que habeis de ser, que yo he venido a señalar la morada que habeis de tener aqui y vivienda que habeis de hacer» (Alcalá 2008: ff26-26v), tal como los dioses indicaron a los uacúsecha dónde debían de vivir al revelárseles en unas piedras de Patzcuaro. «Y mostrábales el suegro [¿el padre del novio?] las sementeras que les daba para sembrar» (Alcalá 2008: f27). 
intercambios de regalos y quien designa el espacio en el que ha de morar la nueva pareja. La asociación entre el patrono y el suegro se ve reforzada por el hecho de que, así como el cazonci está en lugar de Curicaueri, la nueva pareja y en particular el yerno sirven y representan a su suegro ante los demás.

«[Cuando un señor tenía una hija decía:] cásese fulano con tal mujer, porque tengo necesidad de su ayuda y esfuerzo [... Se recomienda al yerno:] entrando alguno en vuestra casa, dadle mantas. Dice el rey que lo que vosotros diéredes, quél lo da. Que no se puede acordar de todos los caciques y señores para dalles a todos mantas y hacelles mercedes y a la otra gente. Por esto estás aquí tú, señor que te tiene por hermano» (Alcalá 2008: $\mathrm{f} 25-24 \mathrm{v})^{10}$.

Si la relación suegro-yerno es comparable a la de dios-cazonci, podemos suponer que del mismo modo que un padre entrega a su hija como esposa a un tercero, la deidad patrona ofrece el reino al futuro gobernante para que entre ellos se establezca una relación parecida al matrimonio. La referencia más explícita a la equivalencia de funciones entre el dios tutelar y el suegro se encuentra en el caso de la alianza entre Carocomaco y el dios Querenda angapeti, pues ahí no sólo se entrega al futuro señor un territorio y un reino sino también una mujer

«Toma estos atavíos que yo tengo, que son insignías de señor y será como yo. Ve y dile que está una mujer llamada Quénomen ques del pueblo de Huruapa, que es pobre como él, que por ahí anduvo a vender agua y se alquilaba para moler maíz en piedras, que entrambos se casarán, y que no esté en Çacapu, que no ha de ser señor allí otro señor mas de yo; que no ha de estar otro en mi lugar, que yo me soy el señor en Çacapu. Mas que se vaya a ser señor en Quérequaro, cerca de Çacapu, y su mujer que no esté con él, mas en otro pueblo llamado Quaruno» (Alcalá 2008: f112v).

Hemos dicho que el pueblo se veía como descendiente de la divinidad, la cuestión es que nuestra fuente nunca especifica en qué grado. Sin embargo, el hecho de que se llamara curá, «abuelo», a quienes la encarnaban, nos proporciona un valioso indicio que se complementa con el hecho de que, tras la elección de un nuevo cazonci, se exclamara «Ya habemos tornado a hallar padre y madre» (Alcalá 2008: f23v). Así parece ser que en dicho esquema, del matrimonio entre el cazonci y el reino que la deidad ofrece como hija, nace el pueblo que se ha de gobernar.

El hecho de que se hable del territorio como si se tratara de una casa refuerza la imagen de la unión reino-gobierno como un matrimonio ${ }^{11}$. Además, notamos que tal como el gobernante representaba a su reino, un marido parece haber fungido como portavoz de su mujer; a una viuda se decía, por ejemplo, «era conoscido de todos tu marido y a ti te hacía conoscer; por él eres conoscida» (Alcalá 2008: f20v).

En este sentido podemos suponer que, así como la ausencia de boda y negociaciones matrimoniales transforman al marido en raptor, la falta de alianza sobrenatural con-

\footnotetext{
${ }^{10}$ Entre la gente «baja» el suegro simplemente declarabla «si tuviera hacienda ese que te pide, casárase contigo y labrara alguna sementera para darte de comer y sirviérase de tal, y a mí que soy viejo, me guardara» (Alcalá 2008: f28).

${ }^{11}$ Durante la entronización de un nuevo señor se decía: «¿Cómo ha de quedar desamparada esta casa? [...] ¿Cómo había de estar desamparada esta casa y oscura como niebla o anublada?» (Alcalá 2008: ff32v-33v).
} 
vierte al gobernante en usurpador ${ }^{12}$. En última instancia, las relaciones hombre-dios y yerno-suegro son prescindibles, sólo se trata de una cuestión de legitimación. Lo anterior tiene como corolario que la relación entre el pueblo y su patrono, construida bajo el modelo de la filiación, es indisoluble; mientras que así como un matrimonio podía separarse, el vínculo entre el gobernante y el dios podía deshacerse si el primero no cumplía adecuadamente con sus funciones. Nótese al respecto la equivalencia en las recomendaciones que se hacen sobre una mujer en caso de adulterio y sobre el gobernante en caso de negligencia:

«[Al marido decía aquel sacerdote:] —Y tú, señor, si notares a tu mujer de algún adulterio, déjala mansamente y enviála a su casa sin hacelle mal, que no echará a nadie la culpa, sino a sí misma, si fuere mala» (Alcalá 2008: f26v).

«[El recién electo cazonci pide:] —-Si no fuere el que debo ser, si no rigiere bien la gente, si anduviere haciendo mal después de borracho, si hiciere mal a alguno, echáme desta casa mansamente» (Alcalá 2008: f32v).

Así como las viudas de su antecesor se casaban con el recién electo cazonci (Alcalá 2008: f35v), a la muerte de un señor el reino que le sobrevive puede formar una nueva alianza con un sucesor del mismo linaje.

Vimos que en la ceremonia matrimonial se decía que el suegro «tenía por hermano» a su yerno. Considerando lo que hasta ahora hemos visto, podemos suponer que la relación entre el cazonci y su deidad se expresase en los mismos términos; para comprenderlo mejor exploraremos ahora la noción p'urhépecha de hermandad.

Los seguidores de Uazoriquare se refieren unos a otros como «hermanos», sin embargo, el hecho de que en ocasiones estos no se conozcan entre sí, muestra que sólo lo son simbólicamente (Martínez González 2009). Suegros y cuñados son citados como hermanos (Alcalá 2008: f27). E incluso Tangáxoan, Hiripan e Hiquingaje se llaman «hermanos» cuando en realidad son primos (Alcalá 2008: ff104v, 38v) ${ }^{13}$.

Existen algunos casos en los que este «lazo fraternal» implica una cierta sumisión. Cuando implora su ayuda Motecuhzoma se refiere al cazonci como «hermano» (Alcalá 2008: f118); durante su captura Nacá llama «hermanos» a Zetaco y Haramen (Alcalá 2008: f83v) y, más interesante aún, los señores sometidos por los uacúsecha son citados como «hermanos» cuando hacen las paces y aceptan a Curicaueri como deidad patrona: «Señores, seais bienvenidos; quizá sí venis de verdad, seremos hermanos» (Alcalá 2008: f18v). Incluso, a la llegada de los españoles, los tarascos proponen «seamos hermanos por muchos años» (Alcalá 2008: $\mathrm{f50}^{14}{ }^{14}$. Los propios isleños explican qué tipo de relación es la que los lleva a referirse a los chichimecas como «hermanos»:

«-Nosotros en el principio fuímos conquistados de sus antepasados y sus esclavos somos, los isleños. Y llevábamos sus comidas a los rey[e]s, a cuestas, y hachas para ir

\footnotetext{
${ }^{12}$ Tomar a una mujer fuera del protocolo matrimonial estaba mal visto, de hecho se dice de los que se casaban por amores que los padres de la novia se «espantaban» al enterarse (Alcalá 2008: f28).

${ }^{13}$ Los hombres con quienes comete adulterio la primera esposa de Tariácuri la llaman «hermana», la cuestión es que estos no sólo son parte de su pueblo de origen, sino que además son mencionados como sus primos (Alcalá 2008: f91v).

${ }^{14}$ En p'urhépecha, existe la posibilidad de hermanarse a través de un pacto (Monzón 2009: comunicación personal).
} 
al monte por leña y les llevábamos los jarros con que bebían y por esto nos empezaron a decir hermanos, por ser sus gobernadores, y entendíamos en lo que los rey[e]s nos mandaban» (Alcalá 2008: f25).

Así, si recordamos los múltiples casamientos entre autóctonos y chichimecas que describe el texto, podemos deducir que tanto la alianza matrimonial como la conquista son susceptibles de producir 'hermandad'. Incluso en el ejemplo de los sobrinos de Tariácuri podemos observar que esa hermandad no supone una relación igualitaria sino que, en nuestra fuente (Alcalá 2008: f39v), ser mayor o menor implica roles bien diferenciados. «Mayor» alude frecuentemente a una posición de poder, Hiripan, el más viejo de los tres primos aparece varias veces como líder; es al primogénito al que corresponde heredar el señorío y quién rige por encima de los demás (Alcalá 2008: ff43v, 116v).

Esta misma subordinación de un «hermano»a otro se presenta entre un hombre y su familia política, y es probablemente bajo este mismo esquema que el señor debe lealtad y obediencia al dios de su pueblo ${ }^{15}$.

\section{La alianza en femenino}

En un excelente artículo que recientemente publicaron Castro y Monzón (2008) sobre el poder político entre los tarascos del siglo XVI, se conjugan la historia y la lingüística para mostrar las distintas formas en que se vinculaban las unidades sociales y sus gobernantes, ya sea por la pertenencia a un linaje, a un territorio o por la sumisión ante un grupo de mayor fuerza. En su Tercera Parte, la Relación de Michoacán nos describe una compleja organización social cuya estratificación comprendía desde el cazonci, su «gobernador» y su «capitán general» hasta los mayordomos de mantas y sementeras ${ }^{16}$. Sin embargo, si estudiamos con mayor cuidado este documento, podemos darnos cuenta de la existencia de otras formas de poder que no se mencionan en esta sección, sino que casi clandestinamente se deslizan entre los datos más variados de la parte histórica. Nos referimos al poder de las mujeres, algo que en la actualidad es bastante patente en la práctica terapéutica, los cargos cívico-religiosos y la estructura familiar tradicional, pero que parece haberse silenciado en los textos más tempranos (Villar Morgan comunicación personal).

\footnotetext{
15 Ticatame y Tariácuri regalan venados al pueblo de sus respectivas mujeres, mientras que Chapa ofrece cautivos sacrificiales a Cando y Huresqua después de que éstos le dieran mujeres (Alcalá 2008: ff64, 88v, $109 \mathrm{v})$.

${ }^{16}$ La Relación de Michoacán (en Castro y Monzón 2008: 35) hace énfasis en la asociación entre el debido culto a la divinidad y la estabilidad de la población. «[El cazonci dice a los caciques:] — Oyeme esto que te dijere: sé obediente y trae leña para los cúes, porque la gente común esté fija, porque si tú no traes leña. ¿qué ha de ser dellos, si tú eres malo? Entra en las casas de los papas a tu oración y reten los vasallos de nuestro dios Curicaveri, que no se vayan a otra parte». Según Castro y Monzón (2008: 35), «el manojo de leños puede verse como un símbolo de la comunidad; y en este sentido el acarreo de leños al templo es lo que ritualmente mantiene unido y estable al grupo. Por eso, el gobernante debe asegurar la provisión de leña para la hoguera del templo». Esto se confirma, según los mismos autores, en el hecho de que uno de los términos que designa al barrio es uapatzequa «manojo de objetos largos y cilíndricos» (Castro y Monzón 2008: 35). A ello se puede añadir el hecho de que se dijera que aquellos sacerdotes que se encargaban de llevar leña a los templos «tenían a sus cuestas toda la gente», algo que también se hubiera podido decir de un mandatario (Alcalá 2008: f11).
} 
En la Relación de Michoacán (Alcalá 2008: ff10, 13, 18v), se encuentran 125 menciones de mujeres; pocas veces se les identifica por su nombre y en numerosas ocasiones se les vincula a la ebriedad, el pecado, los celos, la cobardía, la desconfianza y la lujuria. Se cita a las féminas como criadas, o ayas, que sometidas al poder masculino apenas alcanzan a mandarse unas a otras dentro de la estratificada sociedad de la casa señorial (Alcalá 2008: ff 11v, 12, 12v, 13), se habla de ellas como de un botín o una suerte de posesión intercambiable (Alcalá 2008: ff22v, 23v, 24v, 35v), e incluso se sugiere que una mujer sólo podía ser conocida en virtud de la reputación de su marido (Alcalá 2008: f20v).

No obstante y aunque aparece como algo aberrante, se habla de una mujer que al morir su esposo ocupa el cargo señorial.

«Quedó su mujer [la de Corocomaco] que ya es vieja y dicen que se pone en lugar del marido, por decir que era señor; y dicen que ella manda el pueblo, ¿dónde se usa que las viejas ni mujeres hagan traer leña para los cues que es oficio de varones? [...] Dicen que aquella vieja llamada Quenomen, por hacerse temer, tiene dos bandas de negro por la cara y que tiene a su lado una rodela y una porra en la mano» (Alcalá 2008: f112v).

En otro pasaje se nos dice que en la conquista de Michoacán, «andaban también las mujeres con los que iban a conquistar y todas sus alhajas [...] hasta las mujeres mandaban los pueblos» (Alcalá 2008: f132). Pudiera pensarse que se trata de casos aislados, mas encontramos que, en el Diccionario Grande de la Lengua de Michoacán (1991: II 106), el término cuhcha es traducido como «reyna, emperadora y suprema». En la Relación de Michoacán (Alcalá 2008: f53v) se explica que «a las mujeres de Castilla llamaban cucháecha, que son señoras y diosas». Y ¿qué decir de la tía de Tariácuri, que le asiste y aconseja en temas tan delicados como la elección de una consorte (Alcalá 2008: ff92, 96-97, 100, 102). Ya en el plano material, podemos mencionar que en el entierro 13 de Uricho el individuo asociado a bienes más numerosos y elaborados fue identificado como femenino, pero los materiales más bien parecen ser típicamente masculinos (Pollard y Cahue 1999: 261-275).

Como sucede con los irecha, existen mujeres que entraron en contacto directo con divinidades específicas, tal es el caso de aquella manceba del señor de Ucáreo que fue tomada por Cuerauaperi hasta conducirla al altar de sacrificios (Alcalá 2008: f36v) -la misma ante quien se apareció Curicaueri bajo la forma de un águila para anunciarle la llegada de los españoles (Alcalá 2008: f37) y ante quienes se mostraron los dioses para hablarle de la caída del imperio tarasco (Alcalá 2008: f37v)-. Podría señalarse que la diferencia entre tal mujer y el cazonci es que ella no funge como representante de la deidad; sin embargo, aquí se explica que

«Hallóse aquella mujer puesta al pie de una encina y no vió en aquel lugar ninguna cosa cuando tornó en sí, más de un peñasco que estaba allí, y vínose a su casa por el monte y llegó a la media noche y venía cantando, y oyóla venir un sacristán de la diosa Cuerábaperi, que abrió la puerta, y despertó los sacerdotes y decíales: —Señores, levantaos que viene la diosa Cuerávaperi, que ya ha abierto la puerta».

Aun cuando en Michoacán no tengamos más ejemplos de mujeres gobernantes, hemos podido encontrar otros casos mesoamericanos que nos podrían ayudar a com- 
prender mejor el funcionamiento de esos poderes femeninos que apenas comenzamos a esbozar ${ }^{17}$.

Ya sea como esposas o como madres del primer tlatoani, diversas crónicas de la región sitúan a las mujeres Ilancuitl y Atotoztli como fuentes de poder en la constitución del linaje señorial mexica; en ambos casos, es la relación con una fémina de Culhuacan la que legitima al tlatocayotl. Sin embargo, también existe una versión en la que no es Acamapichtli quien gobierna por primera vez Tenochtitlan sino Ilancueitl, su mujer; «y su esposo le sucedió en el trono sólo después de su muerte» (Gillespie 1989: 43 citando un pasaje de la Historia de los Mexicanos por sus pinturas).

Tal como ha mostrado López Austin (1989), para los mexica la posibilidad de encarnar a las divinidades no estaba en modo alguno restringida al sexo masculino. Entre las más célebres mujeres-diosas figura Malinalxochitl, la hermana antagónica de Huitzilopochtli que se empeñó en detener a los mexica por medios sobrenaturales (Alvarado Tezozomoc 1991: 28; Graulich 1992). Mujeres como Chimalma y Chimallaxoch fungieron como custodios de bultos sagrados (Anales de Cuauhtitlan 1992: 18-19; Códice Azcatitlan 1995: f2v). Otras, como Cuacueye, fueron directamente instruidas por una entidad sobrenatural -aquí mencionada como «el diablo» (Anales de Cuauhtitlan 1992: 12)-. En tanto que féminas, como Xiuhtoztzin, Tlacocihuatzin, Cóhuatl, Miáhuatl, Coacueye, Yaocíhuatl, Chichimecacíhuatl, Tlacochue, Iztacxillotzin y Xiuhtlacuilolxochitzin, debieron asumir el rol de gobernantes (Anales de Cuauhtitlan 1992: 6, 7, 13; Chimalpahin 1998: I 219-221, 353, II 43, 61-63, 67, 251, 281, 363-367; López Austin 2010: comunicación personal; Schroeder: 1994, 269-278). De Xiuhtoztzin se dice que, siendo la hija menor de Quahuitzatzin, comenzó a fungir como cihuatlatoani porque su padre no tuvo vástagos varones. Mientras su hijo alcanzaba la edad suficiente para ser tlatoani, Tlacocihuatzin asumió el gobierno en sustitución de su marido. Pero más interesante aun es el caso de Xiuhtlacuilolxochitzin quien adquirió el poder señorial en virtud de su contacto con entidades sobrenaturales.

«11 tochtli. En este año se entronizó la señora Xiuhtlacuilolxochitzin. Estaba en su casa pajiza en la orilla de la plaza, que está hoy en la orilla del peñasco. Y la causa por que a esta señora le traspasó Huactli el pueblo, se dice que es porque fue su mujer, y que invocaba al 'diablo' Itzpapálotl» (Anales de Cuauhtitlan 1992: 7).

Sabemos que, en los casos chalcas, las cihuatlatoque tenían las mismas facultades que los gobernantes masculinos e incluso eran sus descendientes, preferentemente varones, quienes heredaban el señorío ${ }^{18}$.

En el área maya, se han encontrado restos de mujeres con ajuares funerarios tan lujosos como los de los gobernantes varones. En las estelas del Clásico se les observa igualmente con faldas de jade y tocados de plumas preciosas (Benavides 2007: 117). De hecho, aquí los casos de regidores femeninos no son del todo raros, sino que, de

\footnotetext{
${ }^{17}$ Agradecemos a Manuel Herman por sus atinadas sugerencias bibliográficas.

${ }^{18}$ A esto se suma ese gobernante masculino que adoptaba un rol femenino, conocido como cihuacoatl «Mujer-serpiente» o «Serpiente femenina» (ver Graulich 2001: 8). Nos parece exagerado afirmar, como hace Rodríguez Shadow (2007: 69) que «los puestos que otorgaban poder, prestigio o conocimiento eran acaparados por los hombres [...Las mujeres] estaban excluidas del poder político y social y en el terreno mítico eran rechazadas, acusadas y asesinadas».
} 
acuerdo con Martin y Grube (2000: 14), en el acceso al poder, el criterio dominante era la primogenitura pero, cuando una dinastía estaba por extinguirse, era posible que emergieran algunas reinas. Al menos en el caso de la «reina Xooc»-que, en el dintel 25 , aparecen en actitud de penitencia frente a un ancestro divinizado-, contamos con evidencias de contacto directo con seres sobrenaturales. Mientras que, de acuerdo con el dintel 54 del mismo sitio, la señora Chak Joloom -merecedora del título de sajal, asociado a prácticas militares y rituales- fue custodio de un bulto sagrado (Vega Villalobos 2008: 22, 30-34).

Aunque no contamos con datos precisos sobre la existencia de mujeres gobernantes en el Posclásico, los documentos sobre la Rebelión de Cancuc nos muestran el caso de una joven llamada María de la Candelaria que, después de haber encontrado en el bosque a la Virgen, se convierte en su custodio, encarnación y portavoz para encabezar una sublevación que pretendía poner fin al dominio español. Lo más relevante es que aquí tampoco se trata de un evento insólito, sino que, a lo largo de los siglos XVII y XVIII, se presentaron otras mujeres-diosas en los Altos de Chiapas (ver Viqueira 1997).

Entre los mixtecos prehispánicos, Rosell (2003: 29) ha identificado a tres personajes femeninos que ocuparon roles de gran importancia: la reina 9 Viento, Q Chi, su hija 6 Mono, Ñu Ñu, y la sacerdotisa 9 Hierba, Q Cuañe que representaba a la diosa de la tierra y la muerte. Entre otras cosas, el Códice Selden (5-III en Rosell 2003: 54) nos presenta la imagen de 9 Viento haciendo una ofrenda al bulto sagrado de su pueblo. Terraciano (2005: 348) muestra que, durante la primera mitad del siglo XVI, quien se encontraba a la cabeza de una entidad política era una pareja gobernante y cuando el marido moría era su mujer quien quedaba al mando ${ }^{19}$. Incluso después de la conquista los españoles reconocieron la importancia de las mujeres en la política regional $\mathrm{y}$, aunque perdieron mucho de su poder, les otorgaron el título de cacica y asignaron un sueldo acorde a su jerarquía (Terraciano 2005: 353). Sabemos que, al menos ocasionalmente, las señoras podían trasmitir el mando a sus hijas y, aunque no contamos con referencias directas a la existencia de mujeres-diosas gobernantes, tenemos como indicio el hecho de que doña Catalina, la señora Texupa, llevara el nombre del patrono de su pueblo (Terraciano 2005: 355).

Por lejano que sea, no está de más recordar el caso de la colla de los antiguos quechuas -la esposa-hermana del inca que, representando a la luna, dirigía el gobierno del Cuzco en su ausencia (Metraux 1970) ${ }^{20}$.

\footnotetext{
${ }^{19}$ Entre otras cosas, se subraya el hecho de que, a diferencia de lo que sucede en el centro de México, en los códices mixtecos quien figura sobre el símbolo real del petate (estera) no es un hombre solo, sino un varón y una fémina dispuestos frente a frente (Terraciano 2005: 348).

${ }^{20}$ Dada la similitud entre el p'urhépecha y las lenguas de la familia quechua-aymara, no nos parece descabellado suponer que hubiera cierto parentesco entre ambas clases de poderes femeninos. Entre las evidencias de contacto se encuentran: un cierto léxico compartido (Liedtke 2001: 57-68; Seler 2000: 151-152; Swadesh 1967-68), el desarrollo de técnicas metalúrgicas equivalentes (Hosler 2005) y la existencia de un comercio transpacífico entre Occidente y Ecuador (Anawalt 2000). Sobre este último punto, el argumento más contundente proviene de la carta que el contador real Rodrigo de Albornoz escribió al rey en 1525; pues, en ella se dice que los indios de Zacatula «aseguraban que sus padres y abuelos les habían dicho que de tiempo en tiempo venían indios a dicha costa de ciertas islas del sur en grandes piraguas, trayendo excelentes objetos para comerciar y llevando otras cosas de la tierra. Algunas veces, cuando el mar se ponía bravo, los que venían tenían
} 
Así, aun cuando los datos son escasos, podemos observar que, en todos estos ejemplos, las mujeres gobernantes adquieren su papel ya sea porque establecen una alianza individual con la deidad o porque sustituyen a un varón fallecido. Aunque estas dos circunstancias no parecen tener relación entre sí, un estudio más detallado revela que, también en el segundo caso, existe una alianza de la mujer con la deidad.

Durante el matrimonio de Ticatame con la mujer de Naranjan, se dice explícitamente «Aquí tenemos una hermana; llevádsela y ésta no la damos a Hireti Ticátame, mas a Curícaueri». En el primer matrimonio de Tariácuri, el señor chichimeca da a entender el establecimiento de una relación similar: «traigáisla [a la mujer] en buena hora y esto que me habeis dicho, no lo habeis dicho a mí sino a Curicaueri, nuestro dios» (Alcalá 2008: ff63, 88). Mientras que, como vimos anteriormente, es la propia deidad Querenda angapeti quien elige a Quenomen al entrar en contacto directo con su futuro marido.

En el caso de la mujer de Naranjan, queda claro que tal matrimonio implica la adquisición de obligaciones con el numen de su esposo: «hará mantas para Curícaueri, y mantas para abrigalle y mazamorras y comida para que ofrezcan a Curícaueri» (Alcalá 2008: f63v). Con la hija de un señor, se dice que «ataviaban aquella mujer y liaban su ajuar, y llevaba mantas para su esposo y camisetas y hachas para la leña de los qúes, con las esteras que se ponían a las espaldas, y cinchos» (Alcalá 2008: f26). En otras palabras, así como en la actualidad son los hombres quienes asumen el cargo religioso pero las mujeres le ayudan a desempeñarlo (Alicia Mateo 2008: comunicación oral) $)^{21}$, en la antigüedad debieron ser los varones quienes estaban en lugar de Curicaueri pero las mujeres les ayudaban a cumplir con las obligaciones que se con$\operatorname{trajeran}^{22}$.

Por ahora, no podemos definir con certitud por qué en la Tercera Parte de la Relación no figura ninguna alusión al poder femenino, sin embargo se nos ocurre lo siguiente. Pensando que para comprender la cultura p'urhépecha los evangelizadores debieron emplear los parámetros de su propia cosmovisión y hacer una suerte de traducción, es muy posible que el intérprete de la Relación simplemente no haya «visto» con claridad aquellas formas de poder por el hecho de ser mucho más sutiles. En otros términos, es probable que, al no comprender la compleja red social del estado tarasco, sólo se haya registrado aquello que guardaba mayor semejanza con los aparatos políticos europeos y se haya dejado de lado todo aquello que no pudiera homologarse.

Es interesante notar que algo semejante sucede con los especialistas rituales de tradición prehispánica. La Relación de Michoacán (Alcalá 2008: ff11-11v) presenta una amplia descripción de diferentes tipos de «sacerdotes» y sus actividades respectivas, llegando a un detalle tal que incluso se distingue entre «los que tenían de los pies a

\footnotetext{
que quedarse cinco o seis meses hasta que llegara el buen tiempo, se calmara el mar y pudieran regresar» (en Warren 1977: 10). A estos argumentos se pueden añadir la coincidente división del reino en cuatro partes (Alcalá 2008: f6). Cabe sin embargo aclarar que ninguna de estas afirmaciones nos parece suficiente para sostener, como han hecho Cárdenas Fernández (2003: 65) y Hurtado Mendoza (1986: 14), el origen peruano de la cultura tarasca.

${ }^{21}$ Durante su intervención en el Seminario del Grupo Kw'aniskuyarhani el pasado 29 de marzo de 2008.

${ }^{22}$ Obviamente, discordamos con Rodríguez Shadow (2007: 70), quien afirma que «entre los purépechas existía una ideología que devaluaba a las mujeres y enaltecía el valor de lo masculino».
} 
los sacrificados» y «los que los llevaban arrastrando». Lo que nos llama la atención es que, al contrastar estos datos, con lo que se observa en los vocabularios antiguos, notamos la existencia de otros ritualistas que no aparecen entre los llamados «sacerdotes». Entre los no-sacerdotes citados por el Diccionario Grande de la Lengua de Michoacán (1991: I 85, 119, 200, 297, 360, 366, 484), aparecen el «astrólogo» auandaronapu hurendi, ambogansri, la «bruja» siquame ahchu vanaquareri, el «médico» xurihca, tzinahperi, el «cirujano» xurihca mayahpensri, siripensri, el «embaidor»cacongastahperi, tamhangastahperi y el «ynterprete de sueños» ahtsangariqua teruhtehpensri. Obviamente, es difícil establecer cuáles eran las funciones de estos personajes cuando sólo disponemos de sus títulos, incluso es complicado definir si realmente se trata de roles distintos o si únicamente se usan nombres diversos para calificar cualidades o funciones de un mismo tipo de ritualista. Lo que sí parece evidente es que los que fueron registrados por Alcalá tienen un dominio público, mientras que los omitidos más bien actúan en el ámbito de lo privado.

En la actualidad, las mujeres de Cherán «son la cabeza de la economía doméstica, éstas principalmente se dedican al comercio, en el ámbito ceremonial toman la responsabilidad de wananches [encargadas de una parte del culto religioso] y de cargueras» (Gallardo Ruiz 2005: 51). Acorde a estas formas sutiles de poder, encontramos que la gran mayoría de los ritualistas contemporáneos dedicados a la gestión del infortunio, -enfermedad, pérdidas materiales, malos temporales, etc. - son mujeres (ver Beals 1946; Gallardo Ruiz 2005; Velásquez Gallardo 2000).

\section{La alianza de los hombres en la historia mítica}

Si comparamos las características que la Relación atribuye a lugareños y chichimecas, podemos ver que éstas se encuentran demasiado polarizadas como para ser reales. Las cualidades más destacadas en los lugareños son: el ser viejos ${ }^{23}$, beber alcohol, pescar y sembrar, hablar una lengua «corrupta y serrana», ser ricos, poderosos, lujuriosos, adúlteros y valerse de conjuros o adivinaciones para derrotar a sus enemigos. Entre las particularidades que principalmente se citan para los chichimecas se encuentran: traen leña para sus deidades y se autosacrifican, dan de comer a los visitantes y les ofrecen mantas, no olvidan las injurias, se la pasan haciendo flechas, son castos, no beben, son buenos cazadores, jóvenes y pobres (véase Martínez González en prensa).

Así pues, el ser considerado como chichimeca o autóctono parece más una cuestión de comportamiento que algo relacionado con la filiación o con un modo de vida específico - chichimeca y lugareño serían así lo que Haskell (2008: 234) denomina categorías elementales, «concepciones abstractas y fundamentales representadas por personas»-. Es notable, por ejemplo, que Hiquingaje, sacrificador y penitente pero hijo y nieto de lugareñas, es considerado como chichimeca a pesar de que no se dedique exclusivamente a la caza y lleve una vida plenamente sedentaria. En contrapartida,

\footnotetext{
${ }^{23}$ Aunque se dice que Coringuaro es un pueblo de origen chichimeca, se da a entender que éste lleva tanto tiempo asentado en la región que ha terminado por adoptar las cualidades de los autóctonos.
} 
su medio hermano mayor Curatame, rico, poderoso, ebrio y lujurioso, es citado como un «advenedizo» habitante de Coringuaro. El caso de Tariácuri es particularmente notable, pues, mientras se le llama chichimeca durante toda su juventud casta y guerrera cuando envejece y vive rodeado de sus mujeres, comienza a recordarse su origen isleño. En el mismo sentido tenemos el caso los primos de Tariácuri, Zetaco y Haramen, que siendo chichimecas por estirpe no eran dignos de ser señores porque andaban emborrachándose y con mujeres. Inversamente, se menciona el caso de un lugareño llamado Chapa que se chichimequiza, al menos temporalmente, al adoptar como patrono a Curicaueri y comenzar a ofrecerle cautivos, pero se isleñiza de nuevo al contraer nupcias con una mujer autóctona (véase Martínez González en prensa).

Aun cuando seguramente debió tratarse de procesos sociales sumamente complejos, cabe destacar que, en la Segunda parte de la Relación, el acento no se encuentra en la migración ni en las guerras de conquista ${ }^{24}$ sino justamente en los matrimonios que se entretejen entre autóctonos y recién llegados. De modo que, a pesar de que sí se menciona una cierta preferencia endogámica, al menos en la clase gobernante, la exogamia está lejos de implicar la pérdida de esa «fuerza» o «poder» que menciona López Austin (1976: 219) 25 .

En un trabajo reciente, Haskell (2008) muestra que la historia de los uacúsecha es un discurso coherentemente ordenado en torno a la legitimidad de la estructura de poder. De acuerdo con este autor, en el relato se presentan dos tipos de uniones, las que implican la participación de grupos con cualidades semejantes con resultados nefastos, y las que ponen en juego a partes desiguales, que tienen como desenlace el origen del imperio tarasco. Entre las primeras se encontrarían el matrimonio de Ticatame con la hija del señor de Naranjan donde, tratándose de dos grupos con deidades celestes y calóricas [Curicaueri es el sol y Uazoricuare, una deidad de la región de Zacapu cuyo nombre significa «calor»], da como resultado la muerte del caudillo, y el casamiento de Tariácuri con la mujer de Curinguaro, donde, siendo ambas poblaciones de origen chichimeca, tiene como resultado en el nacimiento de Curatame, un hombre ebrio y lujurioso, incapaz de gobernar. En cambio, del matrimonio entre Pauacume y la hija del pescador deriva el nacimiento de Tariácuri, unificador del reino y fundador de los linajes que prevalecerían. Como señala Haskell (Haskell 2008: 235 [traducción del inglés del autor]), «este matrimonio unifica categorías fundamentalmente opuestas que portan significado en todos los aspectos de la vida. En esencia, su unificación produce una totalidad, y es, por lo tanto, esta unidad de chichimecas e isleños quien gobernará sobre la tierra».

No obstante, podemos objetar que la unión con la mujer de Zacapu no es tan negativa como se supone ya que, además de producir un hijo apto para ejercer el poder, tiene como consecuencia el robo de Uazoricuare, el dios del monte que «da de comer

\footnotetext{
${ }^{24}$ De hecho, el escrito no dedica más que cinco fojas a la conquista de lo que después sería el imperio tarasco (Alcalá 2008: f131-133).

${ }^{25}$ López Austin (1976: 219) se da cuenta del valor del matrimonio en la adquisición de deidades extranjeras; después de la unión del chichimeca y la hija del pescador dice «el futuro gobernante poseería así la fuerza de ambos dioses, y por ende la posibilidad de gobernar ambos pueblos». Lo raro es que después trata a Tariácuri como un antihéroe, un fracasado incapaz de tener contacto directo con las deidades e inútil para trasmitir el poder a sus hijos (López Austin 1976: 225).
} 
a los hombres» por parte de los chichimecas (Alcalá 2008: f65v). Es interesante notar que, al igual que en el matrimonio con la hija del pescador -donde se cambia carne de conejo por pescado asado-, aquí se alude a intercambios de alimentos (Alcalá 2008: ff64v-65). En otros términos, más que hablarse de buenas y malas uniones, lo relevante parece ser que el arreglo matrimonial abre la puerta a la reciprocidad.

Todavía en la actualidad, los ritos matrimoniales suelen implicar secuencias de intercambios entre las dos familias. En Ihuatzio los ritos de petición implican la permuta de pan por frutas entre la familia del novio y la de la novia (Zantwijk 1974: 181). En Cherán, el novio ofrece pan, cigarros, tequila y charanda a su futura parentela política. «En el tiempo que va desde el sí hasta el matrimonio, es decir, mientras está pedida, en cada fiesta los familiares cercanos del novio le llevan fruta en un chiquihuite o batea a la novia. La novia tiene que corresponder con churipu y corundas» (Jacinto Zavala 1988: 92). En la boda se reparten panes en forma de muñecos, «todo aquel que ha recibido, después debe 'corresponder' con ropa el día de la boda religiosa» (Jacinto Zavala 1988: 93-94). En este múltiple intercambio «es muy mal visto tanto dar de menos como dar de más» (Jacinto Zavala 1988: 96). Las bodas «son incuestionablemente el más amplio y ostentoso despliegue de riqueza y posición social que existe en Cherán» (Gallardo Ruiz 2005: 71). En fin, es el intercambio de regalos lo que simboliza la futura interdependencia entre ambos grupos domésticos.

La diferencia entre los grupos contrayentes parece ligarse a la diversidad de los elementos intercambiados, lo cual, siguiendo a Mauss (1923-1924), tiende a perpetuar el ciclo de don y contra-don: si se devolviera algo de la misma especie se trataría de un pago y con ello se cerraría el circuito; en cambio, al entregarse algo de equivalente valor pero distinta naturaleza se genera un cierto margen de interpretación que siempre permite la duda sobre quien dio y obtuvo más. La extensión del circuito termina por implicar el encadenamiento de otras relaciones semejantes y, a la larga, el interés por el bienestar del socio, en otras palabras, una alianza.

Teniendo en cuenta que los chichimecas y los lugareños son, de algún modo, pretarascos -puesto que ninguno de ellos existía ya como tal al tiempo de la llegada de los españoles-, resulta claro que es la síntesis de sus cualidades la que caracteriza a los p'urhépecha reales. Y es a través de las distintas interacciones entre los gobernantes, las deidades y los pueblos como se va construyendo lo plenamente humano, mitad guerrero-cazador y mitad agricultor-pescador (Martínez González en prensa).

Sin embargo, dentro de esta relación, las posiciones no parecen ser intercambiables pues, en todos los casos conocidos, son los chichimecas quienes toman mujeres y las poblaciones locales quienes las dan. Considerando que en el chichimeca se suelen subrayar las cualidades masculinas, ser buen cazador y guerrero, y en el lugareño se señalan vicios femeninos como la incontinencia sexual ${ }^{26}$, la situación de los chichimecas frente a los autóctonos sería comparable a la del marido frente a la familia de la mujer. Parte de esto se evidencia en el hecho de que, al establecerse una alianza matrimonial entre ambos grupos, son las capacidades cinegéticas las que, puestas a

\footnotetext{
${ }^{26}$ El deseo sexual se asocia a lo femenino; la Relación de Michoacán (Alcalá 2008: f86) nos dice explícitamente que las señoras «son incontinentes». «Las mujeres indias como no tienen honras, no encubren lo que les sucede, antes hacen gala de ello, y tanto más cuanto el hombre es de mayor estima» (Basalenque 1963: 424).
} 
prueba, aseguran el acceso a las mujeres isleñas. Ésta es la prueba que Zurumban hizo pasar a Tariácuri.

«Y estaba un pajarillo llamado Zenzenbo, colgado de una flor questaba chupando la miel y viéndolo Zurunban, díjole a Taríacuri: -iOh, qué hermoso pajarito; señor, fléchale! ¿Cómo? ¿No eres chichimeca? Tírale. Respondió Taríacuri: — Que me place. Yo le tiraré, hermano. Y puso una jara en el arco y ya que le quería tirar, dijo Zurunban: - Mírame a la mano y ve por él y trai hacia acá la flecha. Y como soltase, acertóle y dijo Çurunban: - Hermano, ya le acerté, ve por él. Y iba Zurunban por un herbazal y alzó la jara y el pájaro traíale en la mano y llegando a Taríacuri le dijo: - Cierto que eres chichimeca» (Alcalá 2008: f93v; Haskell 2008: 236).

En el caso del matrimonio entre Pauacume y la hija del pescador, se establece una jerarquía a partir de la valoración diferencial de los alimentos que se intercambian. El pescado que ofrece el isleño sería en adelante el alimento del pueblo, y el conejo asado que aportan los chichimecas sería visto como alimento de la nobleza; los chichimecas cazan y los autóctonos pescan, los chichimecas son gobernantes y los lugareños sus súbditos (Alcalá 2008: f71; Martínez González en prensa; Relación de Ajuchitlan 1987: 38).

Pudiera objetarse que en la mayoría de las relaciones yerno-suegro que hasta ahora hemos tratado, son los dadores de mujeres quienes ocupan la posición dominante, sin embargo, es preciso aclarar que, como se ve en el relato de don Pedro Cuyniarangari, lo que coloca a los isleños en una posición servil no es la alianza sino la conquista (Alcalá 2008: f25). Todos los matrimonios que anteceden el dominio de Michoacán por parte de los chichimecas tienden a acentuar su subordinación a los lugareños, situación que termina por revertirse. Al menos, en la descripción del matrimonio de Cuyniarangari la relación mayor-menor ya parece haberse invertido, pues aquí es un isleño quien obtiene por mujer a una hija del cazonci -un chichimeca-.

Como quiera que sea, lo que nos presenta este relato es la alianza entre chichimecas y autóctonos a través del matrimonio de los primeros con las hijas de los segundos y el nacimiento del pueblo contemporáneo como producto de dicha unión.

Por otro lado, resulta claro que, así como la Relación ignoró casi por completo el tema de los poderes femeninos, también es factible que el grupo de los lugareños contara con una representación política mucho más importante que la que suele reconocer esta fuente. Considerando que dicho texto fue generado por un grupo social particular, respondiendo a motivaciones y circunstancias coloniales, podríamos imaginar que los señores uacúsecha omitieron a otros sectores a fin de resaltar su rol dominante y, con ello, justificar un mayor acceso al poder virreinal ${ }^{27}$.

Tal vez, la idea de un poder dual se vea también reflejada en el hecho de que en Michoacán (lugar Xaratanga) era donde se administraba el poder y Pátzcuaro (asociado a Curicaueri) donde vivía el Cazonci. Un testigo declara: «Todo se llama Mechoacán, mas que se llama Pasquaro como nombre de barrio mas no porque sea dividido de esta ciudad sino todo uno y de una jurisdicción [...] Allí [en Pátzcuaro]

\footnotetext{
${ }^{27}$ Aunque casi está de más decirlo, cabe aclarar que el texto de la Relación de Michoacán no es un discurso inocente, sino que, por el contrario, fue generado con una intención política y, en consecuencia, debemos suponer que los informantes de Alcalá debieron seleccionar una cierta «verdad» y evadir muchas otras.
} 
tenía el Cazonci su casa principal de su vivienda, y que este sitio [Michoacán] no lo tenía el dicho Cazonci sino para venirse a él a negocios» (AGI en Warren 1977: 447). Todo el tiempo se ensalza a los chichimecas, pero a la hora de establecer su única capital eligen a Tzintzuntzan-Michoacán, la ciudad de la deidad del lago. Eso concuerda con el hecho de que los últimos cazonci eran descendientes de Tangaxoan, aquel a quien se revela la diosa acuático-telúrica.

\section{Consideraciones finales}

Según se ha dicho la alianza entre el gobernante y la deidad se producía en tres etapas diferentes: el don por parte del aspirante, el diálogo en el contacto directo, y la entrega del reino y el territorio por parte de la divinidad. Lo específico de este caso radica en que la primera dádiva no obliga a la reciprocidad sino a la negociación pues, de algún modo, la continuidad de la práctica de la ofrenda muestra que, aún después del «contradón», el cazonci se encuentra en deuda.

Como resultado, se obtiene un pacto explícito y personal que aun si se entabla individualmente implica una serie de obligaciones colectivas. El hecho de que hubiera quienes gobernaran sin haber establecido jamás contacto directo con su dios muestra que lo que se obtiene no es la función señorial en sí, sino su legitimidad. No obstante, la existencia de mandatarios que ofrecían leña y sacrificio a sus númenes sin haber establecido con ellos una negociación, también nos hace ver que dicho vínculo podía ser trasmitido en el interior de un linaje. Asimismo, vimos que aunque es el varón quien establece la alianza con la deidad, en ella también queda comprendida su esposa y es gracias a ello que, más allá de los nexos individuales que se puedan establecer, las mujeres pueden convertirse en soberanas en sustitución de sus maridos.

Hemos dicho que entre la deidad patrona, el gobernante y el pueblo, existe una relación triádica que en los mitos fundacionales hace posible que unos y otros se sustituyan mutuamente. No obstante, también se ha observado que los vínculos entre el dios y el gobernante no son de la misma naturaleza que los que cualquiera de ellos establecen con la colectividad. El pueblo mantiene una relación filial tanto con el numen como con el señor, mientras que el vínculo gobernante-dios se nos presenta como producto de la alianza matrimonial que establecen dos varones por intermedio de una mujer, que en este caso es el reino. En ese contexto, el cazonci aparece como yerno de la deidad.

Como miembros de una familia, la comunidad y la divinidad mantienen entre sí un nexo indisoluble -al punto de surgir y desaparecer simultáneamente-, que implica el deber de culto por parte del primero a cambio de la protección y otorgamiento de un territorio por el segundo. Claro que, del mismo modo que los pecados de los vástagos afectan a sus progenitores, las transgresiones del grupo ofenden al dios y desencadenan su castigo. A partir de la negociación con la deidad, se legitima el rol de gobernante que, como marido del reino y padre-madre del pueblo, se convertirá en portavoz de la comunidad y la deidad. Recíprocamente, el pueblo, como hijo, asume las obligaciones del mandatario con la sobrenaturaleza y le ayuda a cumplirlas.

Así la alianza aparece como el término fuerte en el discurso mítico tarasco. Gracias a ella, el especialista ritual se contagia del poder sobrenatural de la deidad con quien 
se asocia, el yerno y el gobernante asumen parcialmente la identidad de suegros y dioses, la mujer participa de los vínculos que su marido entabla, y se incorpora a la alteridad en el proceso de construcción del estado. Sin embargo, cabe aclarar que este proceso no sólo permite compartir cualidades e identidades, sino que al mismo tiempo instaura un orden jerárquico en el que, bajo la metáfora del matrimonio, los roles de padre, suegro y hermano mayor dominan a los de hijo, yerno y hermano menor. El dador de mujeres aparece siempre como superior a quienes las reciben, y es solamente a través de la conquista como al final de la mito-historia el yerno puede ocupar el lugar del suegro en una inversión total de los papeles.

Agradecimientos. Dedico este artículo a mis maestros Michel Graulich y Roberte Hamayon cuyas investigaciones sobre la realeza sagrada y la alianza sobrenatural me han inspirado profundamente. Trabajo realizado con el apoyo del Proyecto SEP-CONACYT «Universo y persona. Una analogía etnohistórica purépecha».

\section{Referencias bibliográficas}

AlCALÁ, Jerónimo de

2000 Relación de Michoacán, edición de Moisés Franco Mendoza et al. Zamora: El Colegio de Michoacán, Gobierno del Estado de Michoacán.

2008 Relación de Michoacán, compilación de Claudia Espejel y desarrollo de Carlos Alberto Villalpando. Zamora: El Colegio de Michoacán.

Alvarado Tezozomoc, Hernando

1991 Crónica Mexicayotl, traducción de Adrián León. México: Instituto de Investigaciones Históricas, UNAM.

«Anales de Cuauhtitlan»

1992 en Códice Chimalpopoca, traducción de John Bierhorst. Tucson: University of Arizona Press.

Anawalt, Patricia Rieff

2000 «Ellos venían a comerciar cosas exquisitas: antiguos contactos entre Ecuador y el Occidente», en El Antiguo Occidente de México. Arte y arqueología de un pasado desconocido, R. F. Townsend y C. E. Gutiérrez Arce, eds., pp. 236-253. Guadalajara: The Art Institute of Chicago - Secretaría de Cultura del Gobierno de Jalisco - Tequila Sauza.

BEALs, Ralph

1946 Cheran. A Sierra Tarascan Village. Washington: Smithsonian Institution.

BASALENQUe, Diego de

1963 Historia de la Provincia de San Nicolás de Tolentino de Michoacán del orden de N.P.S. Agustín, edición de José Bravo Ugarte. México: Editorial Jus.

BENAVIDES, Antonio

2007 «Las mujeres mayas prehispánicas», en Las mujeres en Mesoamérica prehispánica, M. J. Rodríguez Shadow, coord., pp. 113-136. Toluca: Universidad Autónoma del Estado de México. 
CÁRDENAS FERnÁNDEZ, Blanca

2003 Los cuentos en lengua p'orhé: un punto de vista sociocrítico. Morelia: Universidad Michoacana de San Nicolás de Hidalgo - Presses Universitaires de Perpignan.

CASTRo Felipe y Cristina Monzón

2008 «El lenguaje del poder: conceptos tarascos en torno a la autoridad», en Símbolos del poder en Mesoamérica, G. Olivier, coord., pp. 32-46. México: Instituto de Investigaciones Históricas, UNAM.

Chimalpahin Cuauhtlehuanitzin, Domingo Francisco de San Antón Muñón

1998 Las ocho relaciones de Chimalpahin, 2 vols., traducción de Rafael Tena. México: Cien de México - CONACULTA.

Códice Azcatitlan

1995 Comentarios de Robert Barlow, revisión de Michel Graulich, traducción de Leonardo López Lujan y Dominique Michelet. París: Bibliotheque Nationale de France - Société des Américanistes.

Diccionario grande de la lengua de Michoacán

19912 vols., edición de Benedict Warren. Morelia: Fimax Publicistas.

ESPEJEl CARBAJAL, Claudia

2008 La justicia y el fuego. Dos claves para leer la Relación de Michoacán. Zamora: El Colegio de Michoacán.

GALlARDo RuIz, Juan

2005 Medicina tradicional p'urhépecha. Zamora: El Colegio de Michoacán - Universidad Indígena Intercultural de Michoacán.

GiLlespie, Susan Dale

1989 The Aztec Kings. The Construction of Rulership in Mexica History. Tucson: University of Arizona Press.

GraUlich, Michel

1992 «Las brujas en las peregrinaciones aztecas». Estudios de Cultura Náhuatl 22: 8798.

2001 «El simbolismo del Templo Mayor de México y sus relaciones con Cacaxtla y Teotihuacan». Anales del Instituto de Investigaciones Estéticas 79: 5-28.

HASKELL ,David

2008 «The Cultural Logic of Hierarchy in the Tarascan State. History as Ideology in the Relación de Michoacán». Ancient Mesoamerica 19: 231-241.

HoSLER, Dorothy

2005 Los sonidos y colores del poder. Tecnología metalúrgica sagrada del occidente de México. Zinacantepec: El Colegio Mexiquense.

Hurtado de Mendoza, Francisco

1986 La religión prehispánica de los purépechas. Morelia: Linotipográfica «Omega».

Jacinto Zavala, Agustín

1988 Mitología y modernización. Morelia: El Colegio de Michoacán - Gobierno del Estado de Michoacán.

LIEDTKE, Stefen

2001 «Comparación de léxico tarasco-quechua». Alma Mater 20: 57-68. 
LÓPEZ Austin, Alfredo

1976 «El fundamento mágico-religioso del poder». Estudios de Cultura Náhuatl 12: 197 240.

1989 Hombre-Dios. Religión y politica en el mundo náhuatl. México: Instituto de Investigaciones Antropológicas, UNAM.

MARTIN, Stephen y Nikolai GRUBE

2000 Chronicle of the Maya Kings and Queens. Deciphering the Dynasties of the Ancient Maya. Londres: Thames and Hudson.

MARTínez GonZÁLEZ, Roberto

2009 «Dioses propios y ajenos: deidades patronas y realeza sagrada entre los purépechas del siglo XVI». Revista Española de Antropología Americana 39: 53-76.

e.p. «La dimensión mítica de la peregrinación tarasca». Journal de la Société des Américanistes.

Martínez González, Roberto, Aída Castilleja y Arturo Oliveros

e.p. «Caránguirio: un sitio rupestre contemporáneo de la cuenca del lago de Pátzcuaro, Michoacán, México», en Memorias de «Global Rock Art»: Congreso Internacional de Arte Rupestre, 2009.

MAUss, Marcel

1923-24 «Essai sur le don. Forme et raison de l'échange dans les sociétés archaïques». L'Année Sociologique, segunda serie, tomo 1: 30-86.

MÉtrauX, Alfred

1970 The History of the Incas. Nueva York: Random House.

POLlARD, Helen P. y Laura CAHUE

1999 «Mortuary Patterns of Regional Elites in the Lake Pátzcuaro Basin of Western Mexico». Latin American Antiquity 10: 259-280.

«Relación de Ajuchitlan»

1987 en Relaciones geográficas del siglo XVI. Michoacán, edición de R. Acuña, pp. 2648. México: Instituto de Investigaciones Antropológicas, UNAM.

«Relación de Tiripitio»

1987 en Relaciones geográficas del siglo XVI. Michoacán, edición de R. Acuña, pp. 331378. México: Instituto de Investigaciones Antropológicas, UNAM.

Rodríguez SHADOw, María J.

2007 «Las relaciones de género en el México prehispánico», en Las mujeres en Mesoamérica prehispánica, M. J. Rodríguez Shadow, ed., pp. 49-75. Toluca: Universidad Autónoma del Estado de México.

Rosell, Cecilia

2003 «Reinas, princesas, sacerdotisas y guerreras en una saga de la Mixteca alta, del siglo VIII al XI, en el Códice Selden», en Las mujeres y sus diosas en los códices prehispánicos de Oaxaca, de C. Rosell y M. A. Ojeda, pp. 13-101. México: Centro de Investigaciones y Estudios Superiores en Antropología Social - Miguel Ángel Porrúa.

SELER, Eduard

2000 «Los antiguos habitantes de Michuacan», en Relación de Michoacán, pp. 147-233.

Zamora: El Colegio de Michoacán, Gobierno del Estado de Michoacán. 
SCHROEDER, Susan

1994 Chimalpahin y los reinos de Chalco. Zinacantepec: El Colegio Mexiquense.

SWADESH, Mauricio

1967-68 «Un nexo prehispánico entre quechua y tarasco». Anales de Antropología 1.

TERRACIANO Kevin

2005 «Reading Women into Mixtec Writings», en Painted Books and Indigenous Knowledge in Mesoamerica. Manuscript Studies in Honor of Mary Elizabeth Smith, E. H. Boone, ed., pp. 345-361. Tulane: Tulane University Press.

Vega Villalobos, María Elena

2008 «La composición dinástica de Yaxchilán durante el reinado de Yaxuun B’ahlam IV». Estudios de Cultura Maya 31: 17-44.

Velásquez Gallardo, Pablo

2000 La hechicería en Charapán, Michoacán. Morelia: Universidad Michoacana de San Nicolás de Hidalgo.

VIQUEIRA ,Juan Pedro

1997 Indios rebeldes e idólatras: Dos ensayos históricos sobre la rebelión india de Cancuc, Chiapas, acaecida en el año de 1712. México: CIESAS - SEP.

WARREN J., Benedict

1977 La conquista de Michoacán 1521-1530. Morelia: Fimax Publicistas.

ZANTWIJK VAN, Ram

1974 Los servidores de los santos. La identidad social y cultural de una comunidad tarasca en México. México: Instituto Nacional Indigenista. 